\title{
A NOVEL STRATEGY TO ASSESS MOTIVES BEHIND PRIVATE TRANSFERS
}

\section{Kevin Luo ${ }^{\mathrm{a}}$}

\begin{abstract}
This study surveys the conventional methods and their limitations in assessing motives for private transfers. Based on the concept of "effective altruism" - a genuine altruist offers help instead of demanding, this study proposes a normative and discriminative strategy to help distinguish the transfer motives, focusing on whether income transfer persists over time. Its application to Chinese interfamily transfers reveals that altruistic motives do exist but play an insignificant role at the aggregate level.
\end{abstract}

Keywords: Private transfer, transfer motives, altruism, egoism, interfamily transfer JEL Classification: D12, D64, I30

\section{Introduction}

The motivational structure behind non-market transfers is of significant policy interest in economics, as transfer motives influence the function of formal insurance mechanisms and the distributional outcomes. Literature along this line has exploited various analytical tools and revealed some intriguing insights into the transfer behaviours. However, the existing evidence remains mixed, and the research of eliciting motives from observed behaviours is still in its infancy.

This study reviews the conventional approaches in differentiating between the altruistic and egoistic motives behind private transfers ${ }^{1}$. It is shown that, whereas most studies have explored straightforward empirical regularities that are readily testable with accessible

a Kobe University, Graduate School of Economics, Kobe, Japan

Email: 151e441e@stu.kobe-u.ac.jp

I thank Mitoshi Yamaguchi, Tomoko Kinugasa and Kai Kajitani for their valuable comments.

1 In academia (e.g., economics, sociology, psychology, and philosophy), there have been longstanding debates over how to distinguish between altruistic and egoistic motives behind income transfer. For a comprehensive survey, for example, see Piliavin and Charng (1990) and Schokkaert (2006). In general, altruistic and self-interest motives may coexist when donors conduct income transfer. The term "altruism" means that the altruistic motive dominates the self-interest. 
data, they are fundamentally indirect tests of transfer motives. Specifically, these attempts are limited in several aspects: (1) ambiguous linkages between the observed outcome and the motive behind; (2) disregard of dynamic aspects; (3) measurement on a gross basis; and (4) technical obstacles in applications. As a consequence, many of the widely examined hypotheses have pointed to observationally equivalent outcomes that could be caused by different motives, which renders the underlying motive indistinguishable.

To cope with these shortcomings, a novel strategy - focusing on whether income transfer persists over time - is proposed in this study. The logic is conceptually simple: in the standard altruism models, typical agents derive utility from offering help, which means that receiving help from others generates disutility at least for some "effectively altruistic" donors. In this sense, genuine altruists consistently provide transfers with little or no compensation from others (net transfer $\geq 0$ ) over a sufficient period. On the other hand, egoists conduct transfers (net transfer $\geq 0$ ) only if they have or will receive something in return (net transfer $\leq 0$ ) in some time; this leads to an observable identity conversion between net provider and net receiver over a prolonged period.

As an application of the new strategy, this study employs a unique household survey (the China Family Panel Studies) to assess the motives behind interfamily transfers in Chinese society. The descriptive analyses suggest that only a small fraction of the households kept providing or receiving net transfers $(>0)$ over the observation period. As the threshold increases (e.g., net transfer $>$ CNY 1,000), the magnitude of "always-providers" and "always-receivers" proves to be insignificant. Also, for those who have provided or received a sizable amount of transfers in a single year, their behavioural patterns do not seem to persist over time. These findings are in line with the consensus achieved by the existing literature: whereas altruistic motives do play a role in determining transfer behaviours, genuine altruism is insignificant at the aggregate level.

The layout of this study is as follows. Section 2 reviews the conventional methods and their limitations in assessing transfer motives. Section 3 introduces a new strategy. Section 4 applies the new strategy to assess the motives behind Chinese interfamily transfers. Section 5 concludes the study.

\section{Conventional Methods in Assessing Transfer Motives}

Income transfer is a complicated and highly context-dependent issue. Income transfer can be either unilateral or mutual, intra-family or interfamily, intra-generational or intergenerational, inter vivos or post-mortem (such as bequest), monetary or in-kind (such as gifts), anonymous or non-anonymous, within a region or across borders (such as migrants' remittances). 
What characteristics should be examined to elicit the motives behind income transfer? Intuitively, one could interview the donors about their incentives of giving (e.g., Cox and Soldo, 2004; Horioka, 2014); experimental frameworks (such as a dictator game) also seem plausible. Gathering attitudinal information is regarded as an efficient way to elicit motives. However, one should always take subjective judgments with a grain of salt (Schokkaert, 2006). In this study, the literature review will concentrate on the empirical hypotheses that are established to infer motives from actual behaviours.

\subsection{Transfer derivatives do not necessarily imply transfer motives}

In the past decades, the method of "transfer derivatives" - assessing the motives from the determinants of transfer behaviours - has become the most commonly used approach in the research. Its rationale is intuitive: benevolent donors care about the wellbeing of the needy and provide them with help, whereas selfish donors do not behave in a prosocial way ${ }^{2}$. This prima facie reasoning, inspired by Becker and Barro's influential work on altruism, has been translated into readily testable hypotheses for empirical investigations. A large stream of research has related transfer behaviours to providers' and particularly recipients' economic situations: such as current income (e.g., Cox, 1987; Altonji et al., 1997; McGarry, 2016), status of being liquidity-constrained (e.g., Cox and Jappelli, 1990; Guiso and Jappelli, 1991), major lifetime events (e.g., McGarry, 2016), and welfare status (e.g., Brown and Jimenez, 2011). In these empirical studies, the outcome variable is the amount and incidence of income transfer, and the determinant (the "derivative") is the objective and subjective attributes of the recipients and donors ${ }^{3}$.

Many other conceivable "transfer derivatives" have been discovered to infer transfer motives. For example, given that public transfers generally neutralize charitable transfers but presumably have an insignificant impact on exchange-motivated transfers, the rejection of complete crowding-out is widely perceived as an indication of "impure altruism" (e.g., Cox and Jakubson, 1995; Duncan, 1999). In assessing the motives behind intra-family transfers, many authors base their judgments on whether parents divide these resources equally among their children (e.g., Halvorsen and Thoresen, 2010; Chang and Luo, 2015).

2 This study will not specifically distinguish among other coexisting motives of transfer behaviours (such as the incentive to comply with social norms and family traditions) since these motives can be referred to collectively as either altruistic or self-interest scenarios. For example, obedience to moral imperatives is associated with self-interest; income transfer motivated by a pure sense of sympathy is considered a form of altruistic act.

3 Subjective characteristics include individuals' expectations, experience, perception, choice, and so on, often available in retrospective and quasi-experimental surveys. 
Some research borrows the standard approaches used in testing risk-sharing mechanisms (such as the linkages between welfare states of different individuals) to evaluate transfer motives (e.g., Altonji et al., 1992; Schwarze and Winkelmann, 2011).

Whereas the "transfer derivatives" have proven empirically useful, much of their logical reasoning cannot survive close scrutiny. A prime example is the extensively used transfer-income relationship. That is, benefiting the poor could reflect altruism (e.g., Cox, 1987). In a broader sense, however, economists do not count voluntary buying and selling as altruistic behaviours, although trading can produce mutual benefits. It is common for selfish moneylenders to make use of their bargaining position over borrowers in desperate need (Stark and Falk, 1998), as is often the case of usurer and micro-loan companies targeting specifically liquidity-constrained and low-income households to ensure high returns. Moreover, some evidence suggests that people experiencing financial difficulties due to their laziness, relative to those with "legitimate" needs, are less likely to receive external help from others (e.g., Schwartz and Fleishman, 1978). This evidence indicates that donors might have taken into account individuals' earning potential in selecting recipients, which implies "impure altruism".

As another example, unemployed and low-income children usually inherit more than their advantaged siblings, which is widely regarded as the manifestation of paternalistic altruism. However, this superficially family-friendly behaviour could be part of specific exchange mechanisms. There is ample evidence indicating that low-income children provide their parents with greater time-intensive support (e.g., Kohara and Ohtake, 2011); many female children with limited earning capacity choose to become a full-time caregiver for their parents.

On the other hand, since public transfers have substitution effects on both charitable donation and private borrowing, interpreting transfer motives in terms of the crowding-out effect might be misleading. As for other popular hypotheses, it is not very difficult to come up with a couple of counterexamples. As suggested by Cox et al. (2004) and Schokkaert (2006), "transfer derivatives" might not render any verdict concerning the underlying motives, because different motives could reach observationally identical outcomes.

\subsection{Exchange perspective: a complicated but indispensable starting point}

For a rigorous investigation into the transfer motives, the key lies in the distinction between altruism and egoism: self-interest behaviour is a quid-pro-quo scheme that requires something in return, whereas altruistic behaviour does not convey direct benefits to the altruist. An illustrative example is the debate over the motives behind reciprocity. 
Some early research considered the coexistence of two-side transfers, such as parent-tochild and child-to-parent transfers, as a display of mutual altruism (e.g., Kimball, 1987). This earlier proposition, however, has been shifted to the advanced concept that the seemingly altruistic interdependence constitutes a form of egoism ${ }^{4}$.

Focusing on exchange mechanisms is a normative and practical way to distinguish self-interest from altruistic motives. In the past decades, the amelioration of statistical systems has enabled researchers to study transfer motives from the "exchange perspective". This stream of research has primarily concentrated on the motivational structure of intra-family transfers (e.g., Cox and Rank, 1992; Henretta et al., 1997; Norton and Van Houtven, 2006; Park, 2014). The main advantage of focusing on exchange behaviours is the explicit connection between the motive and the outcome. For instance, one could conclude the existence of exchange motives from the observation that those who have provided more assistance to their parents have eventually received more bequest; this is apparently less controversial than relying on some vague bequestincome relationships.

However, data limitations and other operational obstacles have significantly held back the progress of the exchange-perspective analyses. Some are described below.

The gross flow might be misleading: due to data deficiency, rather than measuring income transfer on a net flow basis, many studies have relied on either transfer receipt or transfer payment in assessing transfer motives. Gross flow generally overstates the amount and incidence of income transfer. If there is no concrete information on the relative size of the inflow and outflow, using a gross flow will lead to severe measurement bias and even misinterpretation between the actual donor and receiver ${ }^{5}$.

The importance of dynamic aspects: since altruistic behaviour represents a favour given that does not require a favour in return, altruism itself is a dynamic concept. Similarly, because exchange behaviours are discrete in time, focusing on specific empirical relations within a static model might have missed the point: the "payoff" can be done in earlier or later stages. Accordingly, dynamic aspects are essential in assessing transfer motives.

$4 \quad$ Note that genuine altruism should be unconditional. The benefits of mutual transfers might constitute a necessary condition for the emergence of the reciprocal scheme, which implies the exchange essence of reciprocal behaviours (Sober, 1988; Schokkaert, 2006).

5 For example, in the context of intra-generational transfers (e.g., transfers between friends), it is suspicious to measure transfer receipt on a gross basis because the presumed recipient might have given out non-negligible transfers in the meantime. 
Moreover, the time-discrete nature of transfer behaviours has dramatically complicated the application of regression analyses ${ }^{6}$.

Technical limitations in measuring non-monetary transfers: exchange behaviours often involve non-monetary transfers, for which a crucial problem is the inclusion criterion of time transfers. For example, some work has found robust connections between the frequency of parent-child communication and parents' bequest behaviour, based on which researchers argue in favour of the existence of exchange motives. However, making phone calls does not virtually constitute a sort of labour supply, since the price of its market substitute is trivial relative to its return (the bequest received). Indeed, if parents give more bequest to the children who have provided some subtle services, the underlying motive is closer to altruism than self-interest.

In assessing the motives behind paternalistic transfers, incorporating the multi-period framework and the notion of net flow could be inherently difficult ${ }^{7}$. If, for exam- ple, parents raise their offspring in return for old-age support (a long-term contract), the extant data source is unlikely to cover the entire transaction process, nor can all kinds of time transfers be measured in monetary units to compute the net flow of income transfer.

Regression analyses present only indirect evidence: since pure altruism represents unconditional kindness, directly relating observable characteristics (the "conditions") to altruistic motives might be conceptually illogical. This challenge is well understood by most empiricists, who tend to draw policy implications without diving into the complexity of inferring motives. In the past decade, researchers have turned to regression analyses to search for indirect evidence on transfer motives. For instance, simple regressions can be formulated to test whether public transfers offset private transfers (the policy concern), which bypasses the identification of transfer motives. However, capturing the motive is of equal importance for the understanding of human nature; methodological innovation is a necessity for the research of eliciting motives.

$6 \quad$ In a dynamic setting, researchers study transfer behaviours based on time-discrete observations. Using regression methods means focusing on specific relations among the selected variables, which inevitably overlooks other potential connections in the dynamic aspects. Because the actual behavioural pattern is ex-ante unknown and it generally differs across individuals, researchers have to choose arbitrarily among the leads, lags, and time spans to construct the regression model. For instance, based on a 10-year panel household survey, one could test whether transfer receipts in earlier years reduce the likelihood of transfer receipts in the following years; a reverse causality is also possible; alternatively, measuring transfer income as the average amount over a five-year period also seems plausible. Which specification best describes the world is a highly debatable question.

7 The issue of intra-family transfers is an illustration of the technical limitations in measuring long-term and non-monetary transfers. The same problem holds in many other contexts, such as voluntary behaviours and charitable contributions. 


\subsection{Summary}

In recent years, the research into transfer motives has witnessed an upsurge in the application of aggregate-level data. However, focusing on macroeconomic outcomes would overlook some salient features only observable at the individual level. An alternative strategy is to gather subjectively-assessed information. However, as noted, subjective judgments might not be the first-best instrument for economic analyses.

On the other hand, empirical research has centred itself exclusively on the issue of intra-family transfers. However, technical obstacles prevent any rigorous investigation into the motives behind long-term and non-monetary transfers. An advance has been made by the exploitation of panel household surveys ${ }^{8}$, but these attempts have also been restricted by the narrow definition of income transfer and the limitation of regression analyses.

So far, no study has taken into account all the aforementioned aspects in assessing transfer motives. To close this review, let me quote Schokkaert (2006, p. 171): “As soon as one accepts that it is not really useful to focus exclusively on the motivation of pure altruism (albeit with the desire to reject it) or on the hypothesis of perfect crowding-out (perhaps for political reasons), it turns out that many of the more interesting models with a richer motivational structure are either observationally equivalent or that the data available are not sufficiently rich to be confident about the results of testing the motivational assumptions."

\section{New Strategy}

In Section 2, this study has reviewed the conventional approaches to assessing transfer motives. Overall, focusing on exchange behaviours is considered a complicated but indispensable starting point to eliciting transfer motives. It is shown that a rigorous investigation of transfer motives requires the incorporation of the "exchange perspective", the concept of net flow, and a multi-period framework.

For the above considerations, this study proposes a novel conceptual framework the "dynamic net flow strategy" - as a refinement of and complement to the conventional methods. The rationale is intuitive: a pure altruist augments the welfare of others at a net

8 For example, Silverstein et al. (2002), Hochguertel and Ohlsson (2009), and McGarry (2016) have employed longitudinal datasets to study motives behind intra-family transfers. 
material loss ${ }^{9}$. A simplified altruism model can confirm this reasoning ${ }^{10}$. Consider an agent $i$ who maximizes a logarithmic utility function that is altruistically linked to the welfare (consumption) of an agent $j: U^{i}=(1-a) \ln \left(I^{i}-T\right)+a \ln \left(I^{j}+T\right)$, where $I$ denotes the pretransfer income and $T$ is the income transfer. The optimal solution is $T=a I^{i}-(1-a) I^{j}$, in which the amount and direction of the income transfer depend upon the income levels $(I)$ and the strength of altruistic motives $(a)$.

Turn to a broader altruism model: $U_{t}^{l}=(1-\bar{a}) \ln \left(I_{t}^{i}-\bar{T}_{t}\right)+\bar{a} \ln \left(\bar{I}_{t}^{\text {others }}+\bar{T}_{t}\right)$, in which the agent $i$ 's utility is altruistically linked to many others in a dynamic setting. In a similar vein, $\bar{a}$ measures the strength of the agent $i$ 's altruistic motives; $\bar{I}_{t}^{\text {others }}$ denotes the average income of others; $\bar{T}_{t}$ is the total amount of income transfer (net) from the agent $i$ to other people at the time $t$. Without loss of generosity, the agent $i$ is taken as the donor of the income transfer. The constraint $\bar{T}_{t}=\bar{a} I_{t}^{i}-(1-\bar{a}) \bar{I}_{t}^{\text {others }} \geq 0$, which means that the donor keeps providing net transfers in all periods, will hold at least for some "effectively altruistic" donors who have the desire and the economic capacity to sacrifice own resources to help others. Again, only nonreciprocal behaviours signal altruistic motives.

In other words, "effectively altruistic" donors should persist in offering help with little or nothing in return over a sufficient period (net transfer $\geq 0$ ); otherwise, receiving help from others (net transfer $<0$ ) generates disutility for the altruis ${ }^{11}$. On the other hand, egoistic donors would demand something in return (net transfer $<0$ ) if they have or will conduct transfers (net transfer $>0$ ) in some time; this leads to an identity transition between provider and receiver over the transaction process. Figure 1 illustrates the behavioural pattern of altruistic and egoistic donors, expressed in simple sine functions.

Now turn to the case of transfer receivers. If altruism has become the dominant motive behind the income transfer, the likelihood of receiving consistent transfers should be non-negligible (especially for economically disadvantaged recipients). In contrast, if private transfers are mostly driven by exchange motives, most recipients should repay the "debt" at some point in time.

9 In this study, the observed behaviour is taken as the manifestation of underlying motives, which refer to "effective altruism" or "effective egoism". However, this simplified interpretation does have some blind spots (Sober, 1988). For example, even donors with strong altruistic motives might receive unexpected help from others or fail to conduct transfers due to some reasons. Also, social transfers typically produce some immeasurable benefits (such as reputation) that might be of great interest to the donors. Diving into these details is beyond the scope of the study.

10 For detailed modelling techniques of exchange and altruistic behaviours, see, for example, Rapoport and Docquier (2006).

11 Since the altruist cares about the well-being of others and derives utility from offering help, failing to do so and net welfare losses of the recipients (if the recipients become donors) would be ruled out in the optimization process. 

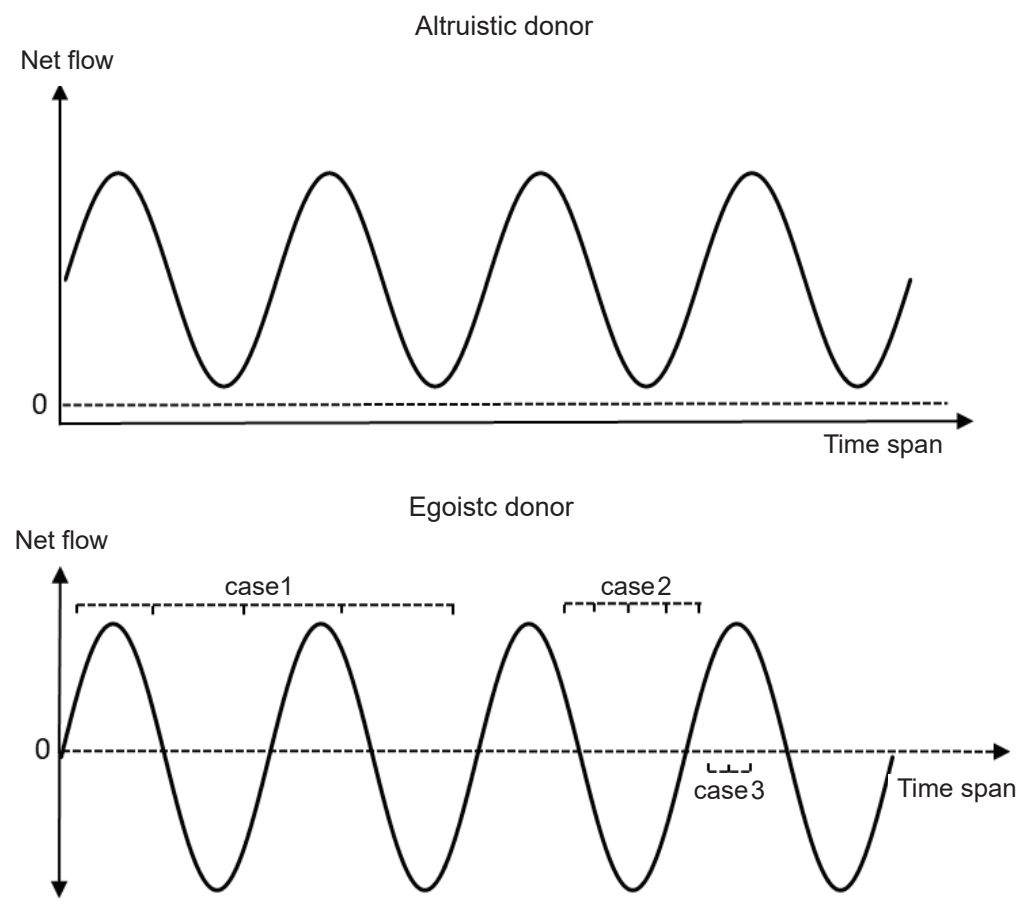

Note: "Net flow" denotes the net transfer from the donor to the recipients.

Source: Author.

This strategy provides a "point-blank" way to capture the transfer motives. It has many advantages over conventional methods. For example, the new strategy is based on a less restrictive assumption: donors have time-invariant transfer motives. Moreover, the new strategy does not depend on statistical inference, thus bypassing the complexity of constructing regression models (see footnote 6). The net flow of income transfer, which is the immediate behavioural consequence of transfer motives, can be assessed by simple descriptive statistics. Most importantly, this approach provides a feasible solution to the "invisibility" of altruism, which is the major challenge confronting the research into motivational structure.

On the other hand, applying the new strategy requires high-quality data, for which the length and frequency of observations can be decisive. As displayed in case 1 of Figure 1, the underlying motives can be distinguished when the information is sufficient. In case 2, a sufficient observation frequency helps to avoid misinterpretation caused by a relatively 
short observation period. If the information is insufficient, as case 3 suggests, the analysis will underestimate the self-interest motives because it did not capture the transition between net provider and net receiver. Data deficiency is a critical issue in the analyses of long-term transfers (such as intra-family transfers) but less problematic for short-term transfers (such as transfers between friends).

\section{Assessing Transfer Motives}

Relative to intra-family transfer, interfamily transfer is more likely an immediate reciprocal scheme that involves less non-monetary exchanges (such as long-term labour supply), which makes the new approach more applicable. The following analysis will look into the motives behind interfamily transfers, on which existing evidence remains scarce.

\subsection{Data}

The China Family Panel Studies (CFPS), conducted by the Institute of Social Science Survey (ISSS) of Peking University, is a database used extensively in investigating household's behavioural patterns. The primary advantage of the CFPS is its panel structure and the detailed information on both the receipt and payment of interfamily transfers, which suits the research purpose of this study. The CFPS follows a strict sampling procedure and contains a unique module, the "soft check", to inspect the credibility of respondents" statements ${ }^{12}$. The respondents in the CFPS are made nearly nationally representative.

The 2012, 2014, and 2016 CFPS report three types of interfamily transfers ${ }^{13}$ : transfers between relatives, transfers between friends, and social donation. After excluding erroneous observations on income transfer, the sample is reduced from 13,316 households (in the 2012 CFPS) to 10,680 households to construct a panel dataset. This sample size will be retained in the subsequent analyses.

Table 1 provides descriptive statistics on interfamily transfers. The left part of Table 1 displays the fractions of households who reported receiving or giving out a certain amount of private transfers (gross) in the survey year. For example, $13.46 \%$ of the respondents received private transfers greater than CNY 1000 in 2012. The right part lists the sample

12 For example, each respondent is asked whether his family has received social donations greater than CNY 2,000 in a single year. If the statement contradicts with the amount reported previously, the respondent will be asked for a re-interview.

13 Similar to other household surveys, the CFPS does not count informal lending/borrowing into private transfers. Transfers between relatives include monetary transfers between parents and children that are registered as separate households. Social donation denotes cash donations and in-kind contributions (measured in monetary units) conducted by anonymous individuals. 
mean and standard deviation regarding each category. For example, the average amount of transfer receipts in 2012 is CNY 1445. Note that the average annual household income of the CFPS respondents is about CNY 55,000 over the survey period.

Table 1: Descriptive statistics

\begin{tabular}{|c|c|c|c|c|c|c|c|}
\hline \multirow{2}{*}{\multicolumn{2}{|c|}{ N: 10680 households }} & \multicolumn{3}{|c|}{ Proportion (\%) } & \multicolumn{3}{|c|}{ Average amount (CNY) } \\
\hline & & \multirow{2}{*}{$\begin{array}{r}2012 \\
21.12 \\
\end{array}$} & \multirow{2}{*}{\begin{tabular}{|l|}
2014 \\
21.05 \\
\end{tabular}} & \multirow{2}{*}{$\begin{array}{l}2016 \\
27.47 \\
\end{array}$} & \multirow{4}{*}{$\begin{array}{c}2012 \\
1,445(7,424)\end{array}$} & 2014 & 2016 \\
\hline \multirow{3}{*}{ Total receipt } & $>$ CNY 0 & & & & & \multirow{3}{*}{$1,163(6,633)$} & \multirow{3}{*}{$1,584(12,661)$} \\
\hline & $>$ CNY 1000 & 13.46 & 13.01 & 13.93 & & & \\
\hline & $>$ CNY 10000 & 2.80 & 2.35 & 2.56 & & & \\
\hline \multirow{3}{*}{$\begin{array}{l}\text { From social } \\
\text { donation }\end{array}$} & $>$ CNY 0 & 0.53 & 1.25 & 1.01 & \multirow{3}{*}{$5(151)$} & \multirow{3}{*}{$9(166)$} & \multirow{3}{*}{$27(1,346)$} \\
\hline & $>$ CNY 1000 & 0.14 & 0.19 & 0.16 & & & \\
\hline & $>$ CNY 10000 & 0.01 & 0.00 & 0.04 & & & \\
\hline \multirow{3}{*}{ From friends } & $>$ CNY 0 & 2.19 & 3.16 & 5.08 & \multirow{3}{*}{$211(2,327)$} & \multirow{3}{*}{$115(1,669)$} & \multirow{3}{*}{$173(3,041)$} \\
\hline & $>$ CNY 1000 & 1.87 & 1.09 & 1.12 & & & \\
\hline & $>$ CNY 10000 & 0.47 & 0.23 & 0.31 & & & \\
\hline \multirow{3}{*}{$\begin{array}{l}\text { From } \\
\text { relatives }\end{array}$} & $>$ CNY 0 & 18.16 & 15.33 & 20.20 & \multirow{3}{*}{$1,229(6,605)$} & \multirow{3}{*}{$1,039(6,149)$} & \multirow{3}{*}{$1,384(11,684)$} \\
\hline & $>$ CNY 1000 & 11.39 & 9.30 & 11.04 & & & \\
\hline & $>$ CNY 10000 & 2.24 & 2.01 & 2.16 & & & \\
\hline \multirow{3}{*}{$\begin{array}{l}\text { Total } \\
\text { payment }\end{array}$} & $>$ CNY 0 & 49.87 & 52.21 & 57.57 & \multirow{3}{*}{$1,329(5,804)$} & \multirow{3}{*}{$1,409(6,783)$} & \multirow{3}{*}{$2,249(22,548)$} \\
\hline & $>$ CNY 1000 & 19.36 & 17.82 & 23.57 & & & \\
\hline & $>$ CNY 10000 & 2.90 & 2.93 & 3.39 & & & \\
\hline \multirow{3}{*}{$\begin{array}{l}\text { To social } \\
\text { donation }\end{array}$} & $>$ CNY 0 & 20.47 & 15.45 & 16.94 & \multirow{3}{*}{$57(268)$} & \multirow{3}{*}{62 (639) } & \multirow{3}{*}{$82(699)$} \\
\hline & $>$ CNY 1000 & 0.67 & 0.67 & 0.93 & & & \\
\hline & $>$ CNY 10000 & 0.00 & 0.03 & 0.02 & & & \\
\hline & $>$ CNY 0 & 7.87 & 6.17 & 7.96 & \multirow{3}{*}{$291(2,517)$} & \multirow{3}{*}{$119(1,307)$} & \\
\hline To friends & $>$ CNY 1000 & 4.00 & 1.84 & 2.90 & & & $202(1,091)$ \\
\hline & $>$ CNY 10000 & 0.35 & 0.12 & 0.26 & & & \\
\hline & $>$ CNY 0 & 23.20 & 24.60 & 28.21 & & & \\
\hline To relatives & $>$ CNY 1000 & 12.45 & 15.06 & 18.42 & $981(4,628)$ & $1,227(6,449)$ & $1,965(22,311)$ \\
\hline & $>$ CNY 10000 & 1.57 & 2.03 & 2.96 & & & \\
\hline
\end{tabular}

Note: The sample consists of respondents who reported either positive or zero values of transfers but excludes those who did not respond to the related questions. "Proportion" denotes the share of households who reported receiving or providing a certain amount of transfers in a single survey year. "Amount" is the monetary value of transfers, expressed in current Chinese Yuan units (CNY). The amount is measured on a gross basis; standard deviation is in the parentheses.

Source: China Family Panel Studies (CFPS) 2012, 2014, and 2016. Information regarding the CFPS is available at http://www.isss.pku.edu.cn/cfps. 
Probably due to the reluctance to report transfer receipts, in addition to the fact that recipients usually account for a small proportion in the total population, transfer receipts appear less widespread than transfer payments. Overall, about 25\% (50\%) of the respondents reported receiving (providing) private transfers, and the average payment is generally more substantial. However, no more than $5 \%$ of the households received or provided transfers greater than CNY 10,000 in each year, implying that sizable transfers do not prevail in Chinese society. The incidence and amount of interfamily transfers are consistent with the degree of social connections: transfers between relatives make up the majority of interfamily transfers, whereas social donation is immaterial at the aggregate level. On the other hand, transfer payments and especially transfer receipts seem to vary considerably across households, which infers the high heterogeneity of transfer behaviours. These results are broadly in line with the previous evidence (e.g., Cox and Jimenez, 1990; McGarry, 2016).

\subsection{Descriptive analysis}

\subsubsection{Proportion of always-givers and always-receivers}

In Section 3, transfers that persist over time are shown to be the behavioural consequence of altruistic transfer motives. Based on this proposition, the strength of altruism can be reflected by the mass of households who consistently received or provided transfers. Table 2 reports the proportion of "always-receivers" and "always-givers" in the full sample. An in-clusion criterion is utilized to allow for concise cross-comparison between the donors and the receivers: positive ( $>\mathrm{CNY} 0)$, moderate $(>\mathrm{CNY} 1,000)$, and significant $(>\mathrm{CNY}$ $10,000)^{14}$.

According to Table 2 , only $0.02 \%$ of the respondents reported receiving continuous social donations (gross) over the survey period; for providers, however, the corresponding ratio is $3.50 \%$. As noted, respondents might be reluctant to report transfer receipts but tend to overstate their transfer payments. In this sense, the self-reported transfer receipt (payment) can be perceived as the lower (higher) bound of the actual income transfer, which helps to evaluate the scope of altruistic motives. Unsurprisingly, charitable donations and transfers toward kith are less prevalent than kinship transfers. For example, only $0.01 \%$ (1.19\%) of the households received gross transfers greater than CNY 1,000 from their friends (relatives) year in and year out over the period.

14 This study has tested alternative inclusion criteria in the classification, such as assessing those who have transferred more than $10 \%$ of their annual income as "generous donors". Different criteria have reached similar conclusions. 
Table 2: Proportion of always-receivers and always-givers

\begin{tabular}{|c|c|c|c|c|c|}
\hline \multirow{2}{*}{ Group } & \multicolumn{5}{|c|}{ Proportion of households in the full sample (\%) } \\
\hline & & donation & friends & relatives & total recepit \\
\hline \multirow{3}{*}{$\begin{array}{l}\text { Transfer receipt } \\
\text { (gross) }\end{array}$} & $>0$ in each year & 0.02 & 0.06 & 2.90 & 3.24 \\
\hline & $>1000$ in each year & 0.00 & 0.01 & 1.19 & 1.33 \\
\hline & $>10000$ in each year & 0.00 & 0.00 & 0.05 & 0.06 \\
\hline \multirow{4}{*}{$\begin{array}{l}\text { Transfer receipt } \\
\text { (net) }\end{array}$} & $>0$ in each year & 0.02 & 0.05 & 2.37 & 2.59 \\
\hline & $>1000$ in each year & 0.00 & 0.00 & 0.95 & 0.99 \\
\hline & $>10000$ in each year & 0.00 & 0.00 & 0.05 & 0.05 \\
\hline & & donation & friends & relatives & $\begin{array}{c}\text { total } \\
\text { payment }\end{array}$ \\
\hline \multirow{3}{*}{$\begin{array}{l}\text { Transfer payment } \\
\text { (gross) }\end{array}$} & $>0$ in each year & 3.50 & 0.22 & 4.88 & 11.59 \\
\hline & $>1000$ in each year & 0.05 & 0.04 & 2.20 & 3.14 \\
\hline & $>10000$ in each year & 0.00 & 0.00 & 0.06 & 0.11 \\
\hline \multirow{3}{*}{$\begin{array}{l}\text { Transfer payment } \\
\text { (net) }\end{array}$} & $>0$ in each year & 3.46 & 0.20 & 3.31 & 8.35 \\
\hline & $>1000$ in each year & 0.05 & 0.03 & 1.66 & 2.35 \\
\hline & $>10000$ in each year & 0.00 & 0.00 & 0.04 & 0.07 \\
\hline
\end{tabular}

Note: This table displays the proportions of households who consistently received or provided certain types of interfamily transfers above specific thresholds in every survey year. The tag "gross" ("net") denotes calculation on a gross (net) flow basis.

Source: China Family Panel Studies (CFPS) 2012, 2014, and 2016.

On the other hand, $11.59 \%(8.35 \%)$ of the households are identified as always-givers in gross (net), implying that the net flow basis has largely reduced the misinterpretation between the actual donor and receiver. Overall, always-givers and always-receivers constitute an insignificant proportion of the full sample. Only $2.35 \%(0.99 \%)$ of the households reported having provided (received) net transfers of more than CNY 1,000 in every survey year $^{15}$. Given that the self-reported transfer payment can be perceived as the higher bound of the actual income transfer, the "effectively altruistic" donors account for less than 3\%

15 Given the household income level (CNY 55,000 annually, on average), the three-year CNY 1,000 criterion seems reasonable. 
of the total population (in the context of interfamily transfers). This evidence indicates the necessity of improving formal insurance mechanisms in Chinese society ${ }^{16}$.

\subsubsection{Dynamics of transfer behaviours}

The previous part evaluated the magnitude of altruistic transfer motives at the aggregate level, based on the three-year same-amount criterion. Since the transfer amount may fluctuate over time instead of being constant (see Figure 1), the above analysis might have underestimated the altruistic motives. For this consideration, the following part will focus on the dynamics of transfer behaviours and look into the evolution of transfer amount and incidence.

The households are divided into 12 groups by transfer amount, direction and survey year. "Net receiver" ("net giver") denotes households who received (provided) nonnegative net transfers; "effective receiver" ("generous giver") denotes households who received (provided) net transfers greater than CNY 10,000. Table 3 displays the results.

According to Table 3, 7303 households received non-negative net transfers in 2012 (CNY 1,778 on average). However, the net receivers in 2012 received much less in the following years, and many of them even became net donors in 2016 (CNY - 170, on average); this suggests a quid-pro-quo nature of private transfers. When the threshold rises (i.e., net receipt or net payment $\geq \mathrm{CNY} 10,000$ ), the transfer amounts differ more significantly across different periods. On average, "generous givers" in 2012 provided only CNY 76 in 2016, which is small in both an absolute and a relative sense. On the one hand, they reduced their transfer payments drastically after 2012 (CNY 22,562 in 2012 versus CNY 76 in 2016). On the other hand, the payment in 2016 is even below the average (CNY 76 versus CNY 665), which means that "generous givers" are less likely to provide transfers in other periods. According to the definition of "effective altruism", inconsistent transfer behaviours signal self-interest; thus, interfamily transfers are mostly driven by exchange motives.

Table 4 displays the incidence of transfer receipts and payments, focused on the "effective receiver" and "generous giver" defined above. Overall, the results support the view that altruistic behaviours do not persist over time. Specifically, only $10 \%$ of the effective receivers in 2012 kept receiving net transfers in later periods, whereas $14 \%$ became net donors in both

16 One might argue that China's outstanding economic growth could lower the demand for informal insurance mechanisms, thus leading to an underestimation of the altruistic motives. However, this is probably not the case. There is overwhelming evidence that China, with underdeveloped financial markets, has been experiencing a growth slowdown and an asset price inflation since 2010 . These factors stimulated the need for non-market transfers. Moreover, it is shown that over half the population has been involved in private transfers (see Table 1). In this sense, Chinese households indeed take part in non-market transfers, but they might not do it "for free". 
2014 and 2016; this means that 76\% of the effective receivers in 2012 failed to become net receivers in either 2014 or 2016 . For generous givers, the likelihood of providing net transfers greater than CNY 5000 in the other two years is less than 12\%. Overall, most participants of interfamily transfers displayed identity changes over the observation period, which indicates a self-interest transfer motive (see Figure 1). These findings correspond to the evidence of Hochguertel and Ohlsson (2009) and McGarry (2016): only a tiny fraction of households received consecutive transfers over an extended period.

Table 3: Evolution of transfer amount

\begin{tabular}{l|c|c|c|c}
\hline Group/Transfer receipt (CNY) & in 2012 & in 2014 & in 2016 & Obs \\
\hline Net receiver in 2012 & 1,778 & 255 & -170 & 7,303 \\
\hline Net receiver in 2014 & 477 & 1,532 & 206 & 7,345 \\
\hline Net receiver in 2016 & 387 & 188 & 2,104 & 7,070 \\
\hline Net giver in 2012 & $-3,478$ & $-1,329$ & $-1,736$ & 3,377 \\
\hline Net giver in 2014 & -613 & $-4,161$ & $-2,584$ & 3,335 \\
\hline Net giver in 2016 & -415 & $-1,094$ & $-6,089$ & 3,610 \\
\hline Effective receiver in 2012 & 29,186 & 2,630 & 1,098 & 335 \\
\hline Effective receiver in 2014 & 3,574 & 28,759 & 4,153 & 294 \\
\hline Effective receiver in 2016 & 1,728 & 2,298 & 35,716 & 326 \\
\hline Generous giver in 2012 & $-22,562$ & $-4,179$ & -76 & 324 \\
\hline Generous giver in 2014 & $-2,360$ & $-22,634$ & $-5,771$ & 390 \\
\hline Generous giver in 2016 & $-1,535$ & $-5,435$ & $-32,887$ & 484 \\
\hline Average of all households & 116 & -245 & -665 & 10,680 \\
\hline
\end{tabular}

Note: This table displays the evolution of the average transfer amount for different groups of households. The amount (net) is calculated as the difference between transfer receipt and payment. "Net receiver" denotes households who received not less than the amount they provided (net receipt $\geq 0$ ). "Net giver" denotes households who provided more than the amount they received (net receipt $<0$ ). "Effective receiver" denotes households whose transfer receipts exceeded their transfer payments by at least CNY 10,000 (net receipt $\geq 10,000$ ). "Generous giver" denotes households whose transfer payments exceeded their transfer receipts by at least CNY 10,000 (net receipt $\leq-10,000$ ).

Source: China Family Panel Studies (CFPS) 2012, 2014, and 2016.

On the other hand, effective receivers and generous givers have displayed an aboveaverage consistency in transfer behaviours. For instance, 32\% of the generous givers in 2012 kept providing transfers in 2014 and 2016, whereas only 2\% became net receivers 
in the following years; 7\% of the effective receivers in 2014 received over CNY 5,000 in 2012 and 2016, whereas only 1\% provided transfers greater than CNY 5,000 in the other years. Unsurprisingly, households involved in sizable transfers are more likely to be altruistically driven, although they account for only a small proportion in the total population. In this sense, altruistic motives do exist and play a role in determining transfer behaviours (Piliavin and Charng, 1990).

Table 4: Evolution of transfer incidence

\begin{tabular}{l|c|c|c|c}
\hline \multirow{2}{*}{ Group/Proportion of households who } & \multicolumn{2}{|c|}{ provided net transfers (\%) } & \multicolumn{2}{c}{ received net transfers (\%) } \\
\cline { 2 - 5 } & $\mathbf{0}$ & $\mathbf{0} \mathbf{5 0 0 0}$ & $\mathbf{0}$ & $\mathbf{2} \mathbf{5 0 0 0}$ \\
\cline { 2 - 5 } & \multicolumn{3}{|c}{ in the other two survey years } \\
\hline Effective receiver in 2012 (335 obs) & 13.73 & 2.39 & 10.45 & 3.58 \\
\hline Effective receiver in 2014 (294 obs) & 12.59 & 0.68 & 13.27 & 6.80 \\
\hline Effective receiver in 2016 (326 obs) & 12.27 & 1.84 & 15.03 & 5.21 \\
\hline Generous giver in 2012 (324 obs) & 31.79 & 11.11 & 2.47 & 1.54 \\
\hline Generous giver in 2014 (390 obs) & 35.90 & 8.97 & 1.79 & 0.77 \\
\hline Generous giver in 2016 (484 obs) & 31.61 & 8.47 & 1.86 & 0.83 \\
\hline
\end{tabular}

Note:Thistableillustrates how theidentity of receiverand giverchanges over time, focused on the "effective receiver" and "generous giver". The number of observations is in the parentheses. The percentage denotes the proportion of households who consistently received or provided certain amounts of net transfers in the other two years. For instance, about 14\% (47 households) of the "effective receivers" in 2012 (335 households) provided net transfers in both 2014 and 2016.

Source: China Family Panel Studies (CFPS) 2012, 2014, and 2016.

\section{Conclusion}

This study has reviewed the conventional methods in assessing transfer motives. It is shown that, due to questionable assumptions and practical limitations, many of the widely examined hypotheses are unable to distinguish the underlying motives of income transfer. Based on the discriminative concept that a genuine altruist gives help instead of demanding, this study proposes a new strategy to capture the motivational structure: transfers that persist over time are the behavioural consequence of altruistic motives.

Using a unique panel dataset (the CFPS), the descriptive analyses reveal that over half the Chinese households have participated in interfamily transfers. However, the "always-givers" and "always-receivers" constitute only a tiny fraction of the total 
population. Donors who provided large transfers in a single year tended to provide much less and even become net receivers in other periods; such an identity change also holds in the case of receivers. Unsurprisingly, households involved in sizable transfers have displayed an above-average strength of altruistic motives.

Overall, these findings suggest that altruistic motives do exist but play an insignificant role at the aggregate level. This evidence is consistent with the consensus reached by the existing literature. Due to data deficiency, the empirical part has concentrated on interfamily transfer and left out the discussion on intrafamily transfer, which is admittedly more widespread and less driven by self-interest motives. It remains to be seen whether the evolving statistical systems could enable a rigorous investigation into the motives behind long-term and non-monetary transfers.

\section{References}

Altonji, J. G., Hayashi, F., Kotlikoff, L. J. (1992). Is the Extended Family Altruistically Linked? Direct Tests Using Micro Data. The American Economic Review, 82(5), 1177-1198.

Altonji, J. G., Hayashi, F., Kotlikoff, L. J. (1997). Parental Altruism and Inter Vivos Transfers: Theory and Evidence. Journal of Political Economy, 105(6), 1121-1166.

Brown, R. P., Jimenez, E. V. (2011). Subjectively-assessed Welfare and International Remittances: Evidence from Tonga. Journal of Development Studies, 47(6), 829-845, https://doi.org/10.1080/00220388.2010.501376

Chang, Y. M., Luo, Z. (2015). Endogenous Division Rules as a Family Constitution: Strategic Altruistic Transfers and Sibling Competition. Journal of Population Economics, 28(1), 173-194, https://doi.org/10.1007/s00148-013-0501-9

Cox, D. (1987). Motives for Private Income Transfers. Journal of Political Economy, 95(3), 508-546, https://doi.org/10.1086/261470

Cox, D., Hansen, B. E., Jimenez, E. (2004). How Responsive are Private Transfers to Income? Evidence from a Laissez-faire Economy. Journal of Public Economics, 88(9-10), 21932219, https://doi.org/10.1016/s0047-2727(03)00069-0

Cox, D., Jakubson, G. (1995). The Connection between Public Transfers and Private Interfamily Transfers. Journal of public Economics, 57(1), 129-167, https://doi. org/10.1016/0047-2727(94)01438-t

Cox, D., Jappelli, T. (1990). Credit Rationing and Private Transfers: Evidence from Survey Data. The Review of Economics and Statistics, 72(3), 445-454, https://doi. org/10.2307/2109352

Cox, D., Jimenez, E. (1990). Achieving Social Objectives Through Private Transfers: A Review. The World Bank Research Observer, 5(2), 205-218, https://doi.org/10.1093/wbro/5.2.205

Cox, D., Rank, M. R. (1992). Inter-vivos Transfers and Intergenerational Exchange. The Review of Economics and Statistics, 74(2), 305-314. 
Cox, D., Soldo, B. J. (2004). Motivation for Money and Care that Adult Children Provide for Parents: Evidence from 'Point-blank' Survey Questions, https://doi.org/10.2139/ ssrn. 1144167

Duncan, B. (1999). Modeling Charitable Contributions of Time and Money. Journal of Public Economics, 72(2), 213-242, https://doi.org/10.1016/s0047-2727(98)00097-8

Guiso, L., Jappelli, T. (1991). Intergenerational Transfers and Capital Market Imperfections: Evidence from a Cross-section of Italian Households. European Economic Review, 35(1), 103-120, https://doi.org/10.1016/0014-2921(91)90106-s

Halvorsen, E., Thoresen, T. O. (2010). Parents' Desire to Make Equal Inter Vivos Transfers. CESifo Economic Studies, 57(1), 121-155, https://doi.org/10.1093/cesifo/ifq007

Henretta, J. C., Hill, M. S., Li, W., Soldo, B. J., Wolf, D. A. (1997). Selection of Children to Provide Care: The Effect of Earlier Parental Transfers. Journals of Gerontology Series B, 52, 110-119, https://doi.org/10.1093/geronb/52b.special_issue.110

Hochguertel, S., Ohlsson, H. (2009). Compensatory Inter Vivos Gifts. Journal of Applied Econometrics, 24(6), 993-1023, https://doi.org/10.1002/jae.1071

Horioka, C. Y. (2014). Are Americans and Indians more Altruistic than the Japanese and Chinese? Evidence from a New International Survey of Bequest Plans. Review of Economics of the Household, 12(3), 411-437, https://doi.org/10.1007/ s11150-014-9252-y

Kimball, M. S. (1987). Making Sense of Two-sided Altruism. Journal of Monetary Economics, 20(2), 301-326, https://doi.org/10.1016/0304-3932(87)90018-3

Kohara, M., Ohtake, F. (2011). Altruism and the Care of Elderly Parents: Evidence from Japanese Families. Japanese Economy, 38(2), 3-18, https://doi.org/10.2753/ jes1097-203×380201

McGarry, K. (2016). Dynamic Aspects of Family Transfers. Journal of Public Economics, 137, 1-13, https://doi.org/10.1016/j.jpubeco.2016.03.008

Norton, E. C., Van Houtven, C. H. (2006). Inter-vivos Transfers and Exchange. Southern Economic Journal, 73(1), 157-172, https://doi.org/10.2307/20111880

Park, C. (2014). Why do Children Transfer to their Parents? Evidence from South Korea. Review of Economics of the Household, 12(3), 461-485, https://doi.org/10.1007/ s11150-012-9173-6

Piliavin, J. A., Charng, H. W. (1990). Altruism: A review of recent theory and research. Annual review of sociology, 16(1), 27-65, https://doi.org/10.1146/annurev.soc.16.1.27

Rapoport, H., Docquier, F. (2006). The Economics of Migrants' Remittances. Handbook of the Economics of Giving, Altruism and Reciprocity, 2, 1135-1198.

Schokkaert, E. (2006). The Empirical Analysis of Transfer Motives. Handbook of the Economics of Giving, Altruism and Reciprocity, 1, 127-181.

Schwartz, S. H., Fleishman, J. A. (1978). Personal Norms and the Mediation of Legitimacy Effects on Helping. Social Psychology, 41(4), 306-315, https://doi.org/10.2307/3033583 
Schwarze, J., Winkelmann, R. (2011). Happiness and Altruism within the Extended Family. Journal of Population Economics, 24(3), 1033-1051, https://doi.org/10.1007/ s00148-010-0326-8

Silverstein, M., Conroy, S. J., Wang, H., Giarrusso, R., Bengtson, V. L. (2002). Reciprocity in Parent-Child Relations over the Adult Life Course. The Journals of Gerontology Series B: Psychological Sciences and Social Sciences, 57(1), S3-S13, https://doi.org/10.1093/ geronb/57.1.s3

Sober, E. (1988). What is Evolutionary Altruism? Canadian Journal of Philosophy, 18(sup1), 75-99, https://doi.org/10.1080/00455091.1988.10715945

Stark, O., Falk, I. (1998). Transfers, Empathy Formation, and Reverse Transfers. The American Economic Review, 88(2), 271-276. 